\title{
JOSÉ LUIS L. ARANGUREN: UNA CRÍTICA DE LA DEMOCRACIA Y DE LA IZQUIERDA
}

\section{JOSÉ LUIS L. ARANGUREN: A CRITIQUE OF DEMOCRACY AND THE LEFT}

\author{
Mikel ARAMBuru ZuDAIRE* \\ IES «Plaza de la Cruz» (Pamplona-Iruña)
}

"Nulla politica sine ethica"

(Aranguren, 1996: 418; La democracia establecida, 1979)

ResUMEN: El artículo presenta, en primer lugar, la visión crítica del filósofo español José Luis L. Aranguren (1909-96), sobre la democracia establecida en España y en el entorno occidental y su propuesta de una «democracia como moral». En segundo lugar, se aborda el papel que debería jugar, según Aranguren, una verdadera izquierda política en toda democracia y, a partir del concepto clave de heterodoxia -en este caso en cuanto des-identificación-, se abre una reflexión acerca del propio ser de la izquierda y de las llamadas políticas de la identidad. Por último, a modo de conclusión, se apunta a un posible diálogo del pensamiento arangureniano con debates actuales sobre la democracia y dentro de la misma izquierda en torno a todas esas cuestiones identitarias.

Palabras clave: José Luis L. Aranguren, Democracia, Izquierda política, Heterodoxia, Identidad.

Aвsтract: This article proceeds in three stages. First, I present the critical vision of the Spanish philosopher José Luis L. Aranguren (1909-96) on the type of democracy established in Spain and in the West and his proposal for a "democracy like a morality".

\footnotetext{
* Doctor en Historia y Máster en Filosofía. Profesor titular del Departamento de Filosofía en el IES Plaza de la Cruz (Gobierno de Navarra), c/ San Fermín, 51, 31003 Pamplona-Iruña (Navarra, Spain). Email: aranzumiel@gmail.com
} 
Secondly, I discuss the role that a true political left should play, according to Aranguren, in a democracy and, starting out from the key concept of heterodoxy - in this case conceived as deidentification -, I offer some reflections on the nature of the left and the political claims of identity. Finally, by way of conclusion, I point to a possible dialogue between Arangurian thinking and current debates on democracy and the politics of identity.

KeYwords: José Luis L. Aranguren, Democracy, Political left, Heterodoxy, Identity.

\section{Introducción}

Hace ya treinta años que el prof. Enrique Bonete publicó su tesis doctoral sobre la filosofía de José Luis L. Aranguren (1909-96) -conocido como el pensador de la última Transición democrática española-, en un libro que trataba de las relaciones entre ética, religión y política en la obra del pensador abulense de origen vasco (Bonete, 1989). Fue el primer estudio de conjunto de dicha obra y donde se resumen las principales ideas de lo que voy a abordar en este artículo. En la misma línea de fondo, hay que reseñar algunas aportaciones más recientes como la del catedrático Elías Díaz (2007), discípulo y amigo de Aranguren, sobre la ética y la política del maestro, o el trabajo del prof. Panea Márquez (2015), a modo de personal homenaje, en el que recorre los hitos vitales e intelectuales del filósofo de Ávila, poniéndolo en relación con Unamuno, Ortega y Gasset y hasta con Cervantes. Lo que subraya Panea es la misión y el compromiso de Aranguren, sin desánimo «entre la desmoralización y la ejemplaridad», no sólo en el ámbito socio-económico y político sino especialmente en el moral y cultural, en el que radica la solución al "problema de nuestro tiempo».

En cualquier caso, para este artículo he partido de la fuente directa y principal, a saber, una parte de las Obras completas del propio Aranguren (1995-96), junto a otras posteriores recopilaciones de escritos, sobre todo colaboraciones en prensa, que destacan aspectos parciales referidos a la política española del momento, como la obra confeccionada por el prof. García-Santesmases (Aranguren, 2005), u ofrecen textos seleccionados con lo más esencial de toda la filosofía arangureniana en sus líneas de fuerza, como el libro elaborado por el prof. Carlos Gómez (Aranguren, 2010). En éste se incluye también, a modo de epílogo (371-410), una recordada conversación entre Aranguren, en los últimos años de vida, y el prof. Javier Muguerza, otro de sus grandes discípulos, a pesar 
de las diferencias de ideas y talante, y asimismo maestro de la ética en español, que nos ha dejado hace poco tiempo.

Mi objetivo, en fin, es tratar de darle una nueva vuelta al pensamiento éticopolítico de Aranguren, pues considero que sus ideas, fieles a la heterodoxia como talante vital que él siempre propugnó, aún tienen plena validez para la vigente democracia en el Estado español y, en general, para los actuales y amenazados sistemas democráticos liberales occidentales. Incluyo también su pensamiento sobre la izquierda política con la que se sintió más concernido y no menos crítico, la cual sigue inmersa en una crisis identitaria de la que está queriendo salir en los últimos tiempos incorporando y adhiriéndose precisamente a las llamadas políticas de la identidad.

\section{La crítica de la «democracia establecida»}

Aranguren afronta el tema de la democracia, de modo teórico, ya desde comienzos de los años sesenta del pasado siglo, cuando afirma que ésta nunca puede dejar de ser lucha por la democracia para no destruirse a sí misma o para que no la destruya cualquier antidemócrata extremista de derecha o de izquierda. Con un texto memorable, Aranguren lo expresa bellamente:

La democracia no es un status en el que pueda un pueblo cómodamente instalarse. Es una conquista ético-política de cada día, que sólo a través de una autocrítica siempre vigilante puede mantenerse. Es más una aspiración que una posesión [...] una "tarea infinita» en la que, si no se progresa, se retrocede; pues incluso lo ya ganado ha de re-conquistarse cada día (1995: 111; Ética y politica, 1963).

Pero entrando ya de lleno en el tema central de este epígrafe, me baso en un libro de Aranguren donde abordó la situación política de la España democrática entre los ańos cruciales de 1976 y $1978 .{ }^{1}$ Para nuestro autor, el nuevo régimen, que integraba, formando un «espectro», a poder y oposición (la cual más bien

\footnotetext{
${ }^{1}$ Se trata del titulado La democracia establecida: una crítica intelectual, publicado en 1979, y recogido en el volumen 5 de las Obras completas (en adelante, si no se dice otro libro, 1996). Como este último, el resto de los libros de Aranguren utilizados en el artículo se citan según esa referencia de las Obras completas, a la que se ańaden el título completo del libro original y el año de su primera edición.
} 
hacía, según él, «oposición-oposiciones»), respondía a una política establecida y de nivelación ideológica. La época del militante, sea de partido o de la misma Iglesia (una cuestión, la religiosa, que, como creyente si bien heterodoxo, también le preocupó a lo largo de su vida ${ }^{2}$ ), estaba pasando y el juego de la verdadera política transcurría ya en espacios extraparlamentarios, donde la auténtica oposición era cada vez más de carácter cultural (1996: 523-25).

En efecto, en opinión de Aranguren, aquella transición política en España trajo más bien desencanto ante una llamada democracia implantada por los franquistas en continuidad incluso «legal» con el anterior régimen. Fue una reforma sin ruptura, con una Constitución sin verdadero "proceso constituyente» o desde abajo, es decir, sin revolución, la cual no tiene que ser, como nos lo recuerda Aranguren, siempre cruenta ni violenta (1996: 518). Él distingue entre Constitución meramente escrita y Constitución real o realmente inscrita, pues lo que todo demócrata desea es que la Carta Magna sea el punto de partida o referencia para su realización. Si el 27 de febrero de 1981, a su parecer, es cuando empieza a «correr la sangre de la democracia por las venas de España», con el primer ańo de gobierno del PSOE en 1982 -que se suele tomar como el fin de la transición del franquismo a la democracia formal-, se inicia la democracia real, la vivida (Aranguren, 2005: 29). Tanto la monarquía democrática como la misma democracia no dejaban de ser una invención racional, cultural, moral. Incluso él, que se confesaba no monárquico sin llegar a ser tampoco antimonárquico, añade, conciliador, que «la monarquía no es compatible con el ideal de la democracia, pero sí con el proceso real de una progresiva democratización» (1995: 662; España: una meditación política, 19833).

Hay que subrayar una primera y reveladora reflexión de Aranguren: la democracia necesita «organizarse» por medio de la participación desde un compromiso moral, pues este es su problema real o radical, siguiendo el afortunado calificativo de Elías Díaz y en su sentido etimológico de ir a la raíz (2007: 169), es decir, la «democracia como moral». Sin duda he aquí la expresión clave de todo su

\footnotetext{
${ }^{2}$ Para este tema específico de la religión en el pensamiento de Aranguren me remito a una monografía, en concreto relativa a las cuestiones de la secularización y la laicidad, de la que soy autor y que ha sido fruto, revisado y ampliado, de la investigación realizada para el TFM con el que obtuve el Máster Universitario en Filosofía por la UNED (Aramburu Zudaire, 2017).

${ }^{3}$ Sobre los capítulos de este libro de meditación política de Aranguren, referidos a la situación de Cataluña y Euskadi, he publicado hace poco un artículo al que también me remito (Aramburu Zudaire, 2018).
} 
pensamiento en este tema: «creo en el compromiso político total y eso, y no otra cosa, es lo que entiendo por democracia como moral, democracia como modo de ser» (1996: 530). Sin embargo, confiesa que, "por el empeño y la entrega total que del pueblo entero demanda, [es] un régimen demasiado bueno al que, como "tipo ideal", no cabe más que aproximarse, sin realizarlo pura, plenamente nunca» (Aranguren, 1996: 396-398). Ha de ser, pues, una tarea utópica, además de crítica, más allá de lo posible, ya que «la utopía es el "espíritu" de toda política que no se conforma con ser mera política». La democracia, insiste, es una forma de vivir, una actitud moral sostenida a lo largo de la existencia, no como forma trágica sino más bien como forma utópica de vida (1996: 420-421). Y en otro momento matiza: «el pathos utópico es el más sobrehumanamente humano de nuestros sentimientos» (1996: 433).

Y puesto que la democracia directa resulta imposible por utópica, ha de mantenerse una vinculación estrecha y constante entre los representantes y los representados para que el sistema no degenere en parlamentarismo o partitocracia ni en mera delegación como dejación del gobierno a favor de un «aparato» oligárquico. De ahí que Aranguren y otros como él nunca fueran políticos profesionales, es decir, posibilistas, sino sólo intelectuales o poetas aunque sin abandonar tampoco del todo la política en manos de aquellos profesionales por ser una cosa demasiado importante, una realidad natural o cuasi natural, siguiendo en esto a Aristóteles pero con un discurso incluyente e integral muy contemporáneo:

La democracia se ha de construir desde la relación sexual y la familia; desde los pueblos, los barrios y las asociaciones de vecinos; desde la liberación de las mujeres y la afirmación sindical; desde la protección de la naturaleza frente a su devastación que la «explota» hasta el límite mismo de su agotamiento o su «explosión»; desde un equilibrio, hoy a punto de perderse, entre la población del campo, de los pueblos, de las pequeñas ciudades y la gran ciudad (Aranguren, 1996: 401-402 y 406).

Junto a esa realidad está también la realidad histórica de España, un tema de estricta democracia, en opinión de Aranguren, y en el sentido cultural, que incluye tres vertientes: la unidad estatal, la religiosa y la impuesta en torno a la moral sexual, el matrimonio y la familia (Aranguren, 1996: 407). El de la unidad o pluralidad de Espańa es, en efecto, el problema primero para una nueva izquierda o izquierda cultural, en el que se enfrenta la cultura establecida castellanista-centralista con los hechos nacionales diferenciales, como el catalán, dentro de «las Españas», invocando así un viejo concepto del tradicionalismo 
hispano. Se trata de la transformación de la idea misma de la «España una» cuya pluralidad no debe significar debilitamiento sino un "pujante enriquecimiento vital», siempre y cuando no se caiga en crear excesivas burocracias autonómicas. A juicio de Aranguren, todas las diferentes identidades son compatibles en un mismo Estado pero, cree, no llevamos camino de lograr su articulación como tampoco se consiguió en tiempos de la II República de 1931:

Hoy está a punto de repetirse la historia. La tarea de una comprensión diferente, nueva y antigua, plural de España, es rigurosamente cultural e incumbe a los intelectuales, historiadores y teóricos de la cultura, de las culturas $[. .$.$] es menester «un lento proceso de convencimiento» (Aranguren,$ 1996: 411-413).

Me temo que en estos momentos y hasta la fecha está ocurriendo más de lo mismo. En cuanto a la mutación cultural que supone la nueva moral sexual, esa que disocia el goce erótico de la función procreadora con todas sus consecuencias, y adonde se ha de extender también la democracia, en opinión de Aranguren existe el peligro -en sintonía con debates identitarios muy actuales, como vamos a ver- de "un cambio cultural como superestructura, sin transformación socioeconómica ni compromiso político, que haría parecer "avanzada" [o pseudo progresista, diría yo] a una bohemia dorada y snob conservadora de sus privilegios» (1996: 416). Para Aranguren la política se ha de entender como cambio estructural y cultural, porque no se limita a ir a votar periódicamente sino que se prolonga mucho más allá de ese acto ritual:

La democracia real se realiza desde el oficio y desde la vida [...]. Frente al superficial politicismo al uso, una comprensión política profunda percibe la dimensión política de la vida entera: cultural, religiosa, pluralista nacional y regional, ecológica, administrativa, socioeconómica, profesional, familiar y sexual, de la cotidianidad también. Política que ha de ejercerse comunitaria, directa, participatoriamente, [...que] en los niveles superiores se constituye como representativa, pero sin dejación del poder popular (Aranguren, 1996: 418; la cursiva es mía).

Para Aranguren el ideal de la democracia empieza por el comportamiento político personal. Por ejemplo, parece un mal inevitable que alguien termine dedicándose profesionalmente a la política pero sería exigible que, al menos, antes y deseablemente después se tenga una ocupación laboral conocida y no se viva sin límites de tiempo del «cuento político». Además, los partidos políticos, 
imprescindibles en toda democracia representativa, constituyen un peligro y un problema para la auténtica democracia si se convierten en aparatos de poder, en fines en sí. Y respecto a la misma estructura de poder del Estado reconoce que en ninguno es de verdad democrática. Hace falta, pues, que tanto los estados como los gobiernos, los partidos y la clase política no se cierren sino que se conviertan, utilizando los mismos términos de Aranguren, en un sistema de comunicación del pueblo mismo, organizado en populus, y no atomizado en plebs o masa (Aranguren, 1996: 430-31).

Ya que la participación en los partidos políticos resulta necesaria, ha de hacerse desde una actitud política que prime la vinculación directa con la base propia (barrio, población, región o nacionalidad, sindicato o asociación profesional, universidad...) y después mantener una relación dialéctica con dichos partidos, desde una función de vigilancia y correctivo de su gestión y contra la partidización. Y siempre, fieles a la heterodoxia o herejía política -ese concepto clave del pensamiento de Aranguren, quien solía repetir que la heterodoxia de hoy, en sus diversos ámbitos, llegaría a ser la ortodoxia de mańana-, permanecer «en el umbral o el atrio", ni fuera ni dentro del todo, como una participación sin pertenencia o una asistencia sin adhesión.

Y se pregunta: «una sociedad desmoralizada por el franquismo, arrastrada por la fiebre de consumo y entontecida por la TV, que se niega a percibir siquiera [...] la crisis económica, ¿está disponible para tomar sobre sí la dura tarea ético-política de realizar una auténtica democracia?» (Aranguren, 1996: 536). En aquellos años se sentía una crisis global de la cultura misma, en estado movedizo, dentro de la cual se vivía. Se echaban en falta grandes políticos y estadistas aunque había gente con dotes para la pequeña política, «conversos» diversos (de franquista a demócrata, de comunista a eurocomunista, de socialista marxista a no marxista...), todos más bien cautelosos, dominados por el neotacticismo, el consensualismo o el «yo diría» en lugar del «he dicho» (Aranguren, 1996: 542 43). ¿No nos suena todo muy actual?

Su conclusión es clara: ninguna democracia establecida es plenamente democrática pero no por eso hay que caer en la delegación como dejación, o en la identificación con el líder (culto a la personalidad), o con el partido («mística partidista»), ni tampoco en la alienación por la manipulación político-publicitaria, en la apatía o el desencanto descomprometido: «la actitud política genuinamente moral tiene que ser, a la vez, vigilante y entusiasta, des-encantada y presta 
al re-encantamiento, crítica y esperanzada, des-mitificadora y creyente, escéptica y utópica» (Aranguren, 1996: 556).

Sin duda, los obstáculos de toda democracia están ahí: en primer lugar, como un hecho institucional limitativo, los "poderes fácticos», presentes y anteriores a la Constitución y al nuevo régimen de 1978, como Aranguren repite, no surgido de la nada o tras ruptura con el anterior, probablemente, porque no era posible o porque los españoles no se comprometieron lo suficiente en la ruptura. También limitan las propias estructuras de la democracia, desde el gobierno, el parlamento, hasta los partidos políticos tanto dentro de su juego unitario poderoposición como ad intra actuando antidemocráticamente (abuso de la cooptación en comités directivos y excesiva disciplina interior). Se han convertido así en rígidas organizaciones de cuadros, no tanto de militantes sino de electores, sin base real ni, llegado el caso, disidente frente al aparato del partido. Por tanto, hace falta «una oposición que funcione como tal junto al poder, $y$, cuando sea necesario, frente a él, y una militancia política que, desde la base, responda de la verdadera democracia» (Aranguren, 1996: 557). Democracia, al fin, es distribución en lo posible igualitaria, democratización del poder contra su prepotencia y, por esencia, «omnidireccional».

En consecuencia, la democracia política, insuficiente, ha de ser completada por la social o socioeconómica, tarea pendiente, que no parece la fuera a traer en su tiempo -ni creo ahora tampoco- el neocapitalismo ni aún menos el socialismo estatalista modelo URSS ni siquiera el modelo autogestionario nunca del todo elaborado ni universalizable como tertium quid válido. Además, hay otra tercera dimensión, la democracia cultural, que implica tanto el acceso de todo el mundo a la cultura como la democratización de las mismas instituciones en su estructura (familia, hoy en crisis, instituciones docentes, medios de comunicación, o la misma Iglesia para que abandone de una vez el nacionalcatolicismo) y tiendan a formas más horizontales y descentralizadoras a favor de los marginados de todo tipo y frente a los excesos de una civilización tecnológica que amenaza el equilibrio ecológico y la naturaleza.

Por tanto, estamos ante una revolución cultural, a pesar de los revolucionarios clásicos, una gran tarea que supone nada menos que un cambio total de actitud. La lucha ha de ser en todos los frentes, cada cual en el que pueda, pues una plena democratización cultural envuelve las otras dos, la política y la socioeconómica. Dicho proceso revolucionario, diríamos integral, nos acerca así al plano de la vida diaria que también es antidemocrático, por ejemplo ¿decidimos por 
nosotros mismos el empleo del tiempo? Y concluye: «hay una correspondencia considerable entre las actitudes de la vida cotidiana y las de la vida política y no es posible democratizar éstas en profundidad sin democratizar aquéllas» (Aranguren, 1996: 561).

Para terminar, reserva, con ese objetivo, un papel relevante a la «filosofía -no académica, no oficial u oficiosa, claro- [como] el partido político cultural de quienes no pertenecen a ningún partido político o pertenecen al que sea con muchas reservas». Esto para los jóvenes -con quienes siempre procuró mantener un diálogo social preferente- quiere decir la citada revolución cultural, un modo no-salvaje de subversión, en fin, una subversión moral (Aranguren, 1996: 514). En concreto, de la Universidad y dentro de ella sobre la sección de Filosofía escribe a fines de 1976:

[La filosofía] postescolástica y crítica de todas las escolásticas puede ser otra cosa, no sirve para nada, marginal a todas las tecnologías y a todos los grupos de interés. Hacer de su inutilidad virtud y luchar contra los poderes de este mundo es su único sentido. Los filósofos no deben aspirar nunca a ser reyes [contra Platón]. Han de ser indigentes (Aranguren, 1996: 425).

\section{Izquierda política y heterodoxia identitaria}

Aranguren acepta y parte de la antítesis política derecha-izquierda, aún insobrepasable en un Estado bien compensado, y considera que la derecha, cuando es inteligente y se atiene a la realidad, se suele apoderar parcialmente del programa izquierdista y, al ser presentado por ella, lo hace inevitable realizándolo. Respecto a la izquierda, Aranguren cree, a fines de 1970, que se había evolucionado de la contestación entusiasta de los 60 hacia la revolución cultural del izquierdismo juvenil, pero se preguntaba por qué a nadie se le había ocurrido constituir una nueva izquierda, testimonial, alejada del juego parlamentario. Una izquierda que trabajara por la modificación de las estructuras elementales de la sociedad con vistas a cambiar la vida. Y que se articulara no en un programa, sino a través precisamente del discurso filosófico, de la ya mencionada filosofía como subversión, nutrida de otros saberes, por ser supradisciplinar, incluidos el arte, la poesía o la literatura, para cambiar el mundo (Aranguren, 1996: 519).

Según Aranguren, la España del cambio de 1982 se puede considerar ya centrista, con una izquierda siempre evolucionando, un PSOE no socialista en 
sentido propio ni en su identidad, y una derecha que difícilmente avanza. Opina que el socialismo tendría que legitimarse no con una nueva ideología sino en una "transideología», superación apasionada, vital y moral, de la dicotomía entre socialismo y socialdemocracia, y en el plano de la praxis política (Aranguren, 1995: 658; España, una meditación politica, 1983). En 1984, Aranguren se decanta por lo que denomina una «izquierda neocontestaria», y no como mera alternancia del poder sino para encarnar los auténticos ideales izquierdistas, entonces al parecer en hibernación, tal vez como continúan hoy en día. No se puede permitir la confusión, al menos por parte de los intelectuales donde él se incluye, y que se olvide la fuerza propia de la izquierda:

Esta poderosa metáfora de la izquierda, metáfora y casi metonimia también, procedente de una topografía política según la cual el lugar natural, por decirlo así, de esta fuerza, el lado del corazón, es el opuesto al del poder establecido por encarnar el compromiso permanente en la tarea de transformación de la realidad (Aranguren, 2005: 63).

Por todo ello, era menester un paradójico «partido antipartidos» sin voluntad de poder, para vigilar y denunciar, mitad partido y mitad asociación ciudadana, que no fuera sólo extraparlamentario sino que presionara, y no contra la democracia parlamentaria sino ¡en ella! Pero Aranguren lo tiene claro: ser de izquierda es estar frente al poder. Recoge aquí aquella cita de lord Acton sobre que el poder corrompe siempre, en un grado u otro, y él apostilla que siempre envejece y derechiza. La democracia meramente política, desvinculada de la moral, la política realista o Realpolitik, el arte de la persuasión, de lo posible, es siempre política de derechas, mientras la izquierda imagina y propone: «es de izquierda quien está fuera y a la izquierda del poder, es decir, frente a él», y en su límite utópico -la extrema izquierda- se sitúa contra el poder, contra el dominio del ser humano por el ser humano. Por eso resulta tan difícil conciliar la condición de político activo y ser plenamente de izquierdas (Aranguren, 2005: 65-67).

Su posición respecto a todo poder no deja de ser dialéctica, la del intelectual «solitario-solidario» o «solidariamente solitario», favorable al diálogo desde fuera para disentir también con la oposición: «la acracia sólo es posible que haga cobrar cuerpo real a su espíritu utópico cuando se pone en relación dialéctica con la llamada democracia [de partidos]» (1996: 454). Él mismo parece propugnar que, si individualmente, asistimos a la plena disolución del ser personal o «des-identificación», lo que acontece en el terreno social es el anarquismo, no el decimonónico o el del primer tercio del siglo XX, sino como «modo de 
ser»: «el sistema colectivo libertario es [...] en todos los planos -y concebido antropológicamente como "sistema cultural" [...]-, la utopía de nuestro tiempo" (Aranguren, 1995: 341; Sobre imagen, identidad y heterodoxia, 1982).

A la altura de 1986, a diez años de su muerte, el camino de Aranguren, siempre un poco contracorriente de toda doxa y de lo políticamente correcto, seguía siendo, dicho con sus palabras, «simple prosecución de una moderada pero firme disidencia». En ese mismo ańo, entre la «ambigua nostalgia de los sesenta y la sumisa pragmática de los ochenta», él se reafirma en que «una política cabal tiene que ser, a la vez, ideológica, es decir, ética, y pragmática, o sea, operativa, agible, realizable». Pero el PSOE lo que estaba haciendo entonces era «llamarse de izquierda, ser de centro y correrse a la derecha, con lo cual todo el espectro político queda ocupado por un mismo y solo partido». Pide que, al menos, no se convierta ese pretendido kairós u ocasión de la historia en virtud moral (Aranguren, 2005: 87 y 89-90).

En 1989, y ante las nuevas elecciones generales en España, la sociedad se encuentra atomizada, se ha perdido la identidad social, la "conciencia de clase», aunque cada vez haya más subproletarios, marginados o del llamado cuarto mundo. La novedad mayor es la democratización cultural, por eso la oposición, débil, era más socio-cultural que socio-política. Y Aranguren se sigue haciendo preguntas: ¿cuándo aparecerá una disidencia (como la que él quiere vivir) que configure políticamente esta demanda cultural y sobre todo ética? ¿Estamos dispuestos a exigir al Gobierno que deje de ser espejo de nuestra baja forma moral? (2005: 120-122). Recordemos que para él la palabra moral tiene además del etimológico otro significado equivalente al empleo en el lenguaje deportivo de términos como "baja moral», «desmoralización»o "moral elevada». Es fiel así al sentido del concepto de moral como estructura tomado de Zubiri, a saber, la fuerza propia humana de hacer la vida, el entusiasmo, el ejercicio de la libertad, que se ha de distinguir de la moral como contenido, la de los fines, deberes, valores, la del que hay que hacer (Aranguren, 2005: 126).

Finalmente, en otro artículo de 1990 más extenso para una revista académica, señala los diversos condicionamientos para la existencia de esa «desmoralizada moral» de la época. En lo económico, frente al ethos del protestantismo como espiritu del capitalismo según la célebre tesis weberiana, el capitalismo financiero es el único que ha funcionado bien en la España de tradición católica (estaba por estudiar) y además se había pasado ya a un capitalismo de especulación y de finanzas como escaparate. En cuanto al ámbito político ha quedado clara la 
evolución de la izquierda tras la crisis del marxismo, el aburguesamiento del proletariado y el derrumbamiento del llamado socialismo real. Se vive en una res publica bajo el dominio de la publicidad, la oligarquía de los partidos con sus listas cerradas, su disciplina interna, el "corporatismo" y burocratismo, y los mass media. Y la consecuencia es dicha desmoralización que 40 años antes era apatía política. Por último, en lo internacional, el problema de España es el de Europa, donde está situada al Sur (con Portugal, la Italia meridional y Grecia). Además, se anunciaba entonces el «fin de la Historia» como imposición del capitalismo sin fronteras en casi todo el mundo, aunque todavía quedaba, en su opinión, una incierta posibilidad de que los países del Este europeo encontraran su «tercera vía» política, pues en ellos actuaban varios intelectuales en el poder como el polaco Geremek, el rumano Plesu y sobre todo el checo Havel, que podrían orientar éticamente la política (Aranguren, 2005: 126-138). Bien sabemos ahora que eso no sucedió plenamente.

Un concepto clave del pensamiento y «talante» de Aranguren, no sólo para el ámbito religioso del que procede sino también para el ético-político, es el de heterodoxia que yo me atrevería a conectar con los nuevos discursos de la izquierda que tratan el tema de las llamadas políticas de las identidades. Aranguren propone la heterodoxia como una cuestión «moral y vital» novedosa, unida dialécticamente a la de la imagen y la identidad, pues, si las épocas estables son de primacía identitaria, las inestables, como la del momento en que él escribe (y sin duda también la del presente), están continuamente «des-identificándose» en ellas mismas (1995: 326; Sobre imagen, identidad y heterodoxia, 1982). En efecto, el fundamento de esa concepción moral y de la vida reposa en la heterodoxia, que empieza respecto a sí mismo, un sí mismo roto en mil pedazos, recompuesto y vuelto a romper y de nuevo a recomponer al modo de un caleidoscopio. La personalidad se vive bajo múltiples máscaras y el rostro coincide por turno con cada una de ellas, el «des-nudo» (en castellano no sería, pues, "des-vestido») se manifiesta como vestido o como el mejor disfraz, la identidad como «desidentificación» y la autenticidad como «caracterización» o fabricación de un «carácter». Se trata de un estado, diríamos, muy posmoderno, de "encontrarse perdido”: paradójica locución [un oxímoron se podría decir] que expresa muy bien, a la vez, el predicamento (condición) de la existencia contemporánea, y el predicamento (estimación) contemporáneo de la heterodoxia» (Aranguren, 1995: 411 y 413; Sobre imagen, identidad y heterodoxia, 1982). ¿No nos recuerda esto la actual fluidez del género entre otras identidades líquidas que nos rodean? 
Aún más, Aranguren, con enorme clarividencia para su tiempo y contexto, se interroga si existe de verdad un cuerpo determinado -hecho por quienquiera que sea- uno de cuyos caracteres fundamentales es su sexo. Para él, no es el "travestissement" o apariencia de cambio de sexo lo más radicalmente nuevo sino el transexualismo o transexualidad, «la posibilidad de cambio quirúrgico [...]. Esto altera fundamentalmente la significación del sexo, que se convierte así [...] en mudable». Estamos, en su opinión, ante el caso límite pero, sin llegar a él, lo que altera «la supuesta consistencia o fijeza del sexo en su polarizada funcionalidad» es "la "normalidad" actual de la homosexualidad, la bisexualidad y el polimorfismo sexual» (Aranguren, 1995: 338; Sobre imagen, identidad y heterodoxia, 1982).

$\mathrm{Y}$ añade Aranguren volviendo al plano ético: «el supremo mandato de esta nueva moral [...] es la transgresión de todos los códigos morales, el "errar" más allá de ellos. Por eso mismo, el comportamiento llega a ser estimado como positivo, justamente en cuanto anómico, "desviado" [...] "maldito"». Así se explica la razón del prestigio creciente - «el mundo al revés»- de la homosexualidad y mejor aún de la bisexualidad frente al «puritanismo» homosexual intransigente de la transexualidad, de la "pansexualidad» (hoy hablaríamos del movimiento LGT$\mathrm{BIQ}+)$. Se asiste a una verdadera transmutación de los valores, una nietzscheana transvaloración que no se reduce al simple poner lo de arriba abajo y viceversa, sino que deviene "heterodoxia del errar en la "ab-erración", del desviarse del "buen camino", el ortodoxo, el "natural"». Aranguren advierte, sin embargo, que no está aprobando esa «nueva y extremosa moral» sino sólo describiéndola y lo hace desde una perspectiva, creo, muy actual y anterior a la época de internet, aunque resuene ya en el ancho mundo de las redes sociales donde la privacidad se diluye:

Ni trabajo, ni diversión, ni integración como sentido de la vida, sino "bricolaje" total, vagabundo de la vida, y lúdica marginación dentro de una cotidianidad nada solemne, nada «importante». Mas la vida cotidiana así exaltada no se encierra en una "privacy", posee intimidad real, sí, pero ésta es comunicada, «expuesta», intercambiada (Aranguren, 1995: 412-413; Sobre imagen, identidad y heterodoxia, 1982).

Por último, dentro de toda esa «transgresión del ser», merece un capítulo particular la también «des-identificación» de la mujer. Aunque al tema de la liberación femenina ya le había dedicado Aranguren un título monográfico (1995: 583-647; Erotismo y liberación de la mujer, 1972), ahora la integra en un concepto más amplio de «liberación cultural»: «la mujer tiene que pasar de ser 
"ejecutora" de la partitura que el hombre escribe para ella, a "compositora"; de "actriz" del papel que el hombre le atribuye, a "autora" de su propio papel, de su propia vida». No se trata de una trasnochada identidad de la mujer en tanto que mujer sino de la citada "des-identificación», lo mismo que la del varón, en este caso libre de toda tutela ajena a ella misma, pues no existe un «arquetipo» de la feminidad como tampoco de la masculinidad. Y concluye: «en que la mujer, ejercitando su propia imaginación, se invente, cada día, a sí misma, habría de consistir la plenitud de su liberación [...y], a la vez que se libera, podría contribuir a liberar al hombre de la sujeción de esos papeles [los que, para su desgracia, él mismo ha inventado]» (Aranguren, 1995: 343; Sobre imagen, identidady heterodoxia, 1982).

\section{A modo de conclusión: Aranguren y los debates actuales en torno a la democracia y la izquierda}

Dando un salto de casi cuarenta ańos hasta nuestro tiempo, apreciamos que todas estas cuestiones sobre la democracia, la izquierda política o las identitarias que preocupaban a Aranguren -y en las que, como sobre tantas otras, fue un adelantado-, continúan más vivas y abiertas que nunca en España y en todo Occidente. Sólo como botón de muestra y a modo de conclusión, voy a exponer ciertas ideas de algunos teóricos del ámbito estatal que considero, en algún sentido, próximos ideológicamente al pensador abulense, y que han escrito en torno a estos temas. Con ellos propongo al respecto una conversación hipotética, una tentativa o primera aproximación, a falta de mayor investigación o profundización, en torno a diferencias y similitudes en los enfoques o planteamientos, pues como el mismo Aranguren escribiera a la muerte de su maestro Eugenio d'Ors, «el espíritu no muere, el diálogo prosigue, la palabra no puede extinguirse».

Así, el prof. Juan-Ramón Capella ha reflexionado en su último libro (2019) sobre la democracia española en el cambio de época, justo del que fue protagonista Aranguren, y que va de 1978 con la aprobación de la vigente Constitución hasta el presente. Capella lo califica de «un fin del mundo» por las mutaciones habidas y cuando los problemas no residen en la conquista de las libertades públicas sino en su supervivencia. Hoy las opciones políticas básicas están bajo el dominio de una plutocracia liberal, nuevo soberano superestatal difuso, que limita los espacios de libertad y vuelve obsoleto el discurso político y social tradicional. Es en la última parte del libro donde Capella aborda los amenazados procesos de democratización y argumenta que en el futuro la defensa de la democracia 
se ha de centrar socialmente, ante todo, en la lucha contra las desigualdades y también en el control del crecimiento y el decrecimiento productivo exigido por la gran crisis ecológica global. Para «embridar» aquella plutocracia y en esa defensa de la democracia, habría que constitucionalizar la actividad económica (por ejemplo, con la tasa Tobin), y Capella concluye, muy cercano al pensar de Aranguren, que «resultan inútiles los partidos que actúan exclusivamente en el teatro parlamentario y electoral. Ahí no se construye hegemonía. Esta se gesta en la sociedad civil con activismo inteligente en todos los ámbitos de la cultura social». Se trata de regenerarse o de languidecer y que se profundice la «barbarización» de la sociedad. Él alude a la condición para el funcionamiento democrático de la existencia de una "ciudadanía informada» que constituye el pueblo pero éste, en cuanto población, resulta algo muy complejo.

Otro pensador notable del presente, quien también escribe de la complejidad social actual que parece distanciarnos de la propia democracia, es el prof. Daniel Innerarity (2018; cf. 2020). En efecto, la democracia, "como complicación», necesita unos actores que ella misma es incapaz de producir, pero sin una ciudadanía activa y participativa, formada e informada, con "competencia política», que entienda lo que se debate en el espacio público, es imposible hablar de calidad democrática. Creo que también en la línea de Aranguren pero con otro lenguaje, Innerarity plantea el fortalecimiento de la cooperación y organización institucional de la inteligencia colectiva («reflexión cooperativa»), más allá del esfuerzo individual aunque lo incluya, y no recurrir sólo a «expertos», a la delegación o a la renuncia del control popular. Es la competencia política la que requiere democracia y no tanto al revés, la cual se adquiere «en el contexto de una experiencia de vida democrática común», es decir, llevada a cabo «discursivamente en un espacio público común igualitario e incluyente».

En cuanto al pensamiento de izquierdas, no parece haber encontrado aún una salida satisfactoria a su crisis identitaria, de ideas y estrategia, e incluso se han impulsado más frentes de discusión ante los retos o desafíos que suscitan nuevas realidades sociales o no tan nuevas, más bien realidades históricamente no reconocidas. El nuevo escenario ideológico, que alcanza al ámbito académico de las ciencias humanas y sociales, ha reemplazado la noción de clase por la de identidad. En todo caso, en opinión del prof. Ignacio Sánchez-Cuenca, aún existe una «superioridad moral de la izquierda» (2018), pues postula -mostrando en ello gran afinidad con Aranguren-, que la política tiene raíces morales y que las ideologías son la traslación al ámbito político de principios morales básicos. Y es esta conexión entre moral y política lo que le permite establecer, como tesis 
principal de su libro, dicha superioridad de las ideas izquierdistas (por preferibles), pues en cuestiones morales no cabe el relativismo.

A vueltas con la identidad de izquierda, el político y también politólogo Ínigo Errejón, en el prólogo del citado libro de Sánchez-Cuenca, considera que ninguna experiencia revolucionaria ha construido hegemonía en torno a aquella identidad comparada con la nacional o de clase. Es una de sus tesis ideológicas fundantes que ha venido repitiendo desde entonces en distintos foros y medios (cf. Errejón y Mouffe, 2015). Con ello está apuntando precisamente a la polémica actual en círculos intelectuales progresistas, a saber, si la izquierda posmoderna, imbuida de academicismo y culturalismo, se ha olvidado del hombre medio en favor de un abanico de reivindicaciones de reconocimiento identitario de «minorías sociales diversas» regalando el voto de clase a emprendedores políticos reaccionarios como el presidente estadounidense Trump.

Al hilo de todo esto, y elaborado desde una aproximación periodística y no académica, el escritor Daniel Bernabé (2018) ha centrado el debate en torno al papel de cierta izquierda política y del activismo ante la fragmentación de la identidad de la clase trabajadora por el triunfante neoliberalismo. Éste se ha convertido en propulsor de conflictos culturales en torno a lo simbólico eludiendo así los problemas económicos o laborales y haciendo caer a aquella izquierda en la "trampa de la diversidad». En gran medida respondiendo a esta "trampa" defendida por Bernabé, Sandro Mezzadra y Mario Neumann han publicado un reciente ensayo (2019) en el que reivindican -sin renunciar a un cierto populismo de izquierdas, a la Nueva Izquierda y a la búsqueda del nuevo proletariado- la vigencia del concepto de clase social, pero no la misma del movimiento obrero que perduró casi sin cuestionamiento hasta mayo del 68. La clase hay que repensarla y reformularla, incluida la "conciencia de clase», y plantearla también dentro de la cuestión de la democracia como demanda de una «democracia real», lo cual, dicho así, nos recuerda de nuevo al pensamiento de Aranguren. Sin embargo, ante estas nuevas o mejor irreconocidas realidades o diversidades identitarias, con su terminología y conceptos específicos que ciertos críticos califican de neolengua, tampoco existe unanimidad -quizá no pueda ni es deseable que la haya-, como lo muestra la última polémica, traspasada a los medios y redes sociales, del «feminismo crítico y abolicionista de género» con el movimiento LGTBIQ+ en torno a la teoría queer y el transexualismo. ${ }^{4}$

${ }^{4}$ Cf. Manifiesto del verano de 2019, tras las XVI Jornadas celebradas en Gijón, de la Escuela de Feminismo Rosario de Acuña [En línea] «https://docs.google.com/ 
Parece no haber, por consiguiente, una única manera de ser de izquierdas y de actuar como tal en una democracia liberal o representativa. Así, otros intelectuales como el prof. Félix Ovejero (2018), desde una perspectiva «de siempre», es decir, más ilustrada, emancipadora y racional, ha advertido de la «deriva reaccionaria» de toda esa izquierda política reciente que ha recalado en un puro romanticismo tradicional comprensivo tanto de la sinrazón supersticiosa de las religiones como de las comunidades políticas sostenidas en la identidad etno-cultural, que duda incluso del progreso científico, y es contraria al proceso globalizador y a la expansión de los mercados para ampliar la productividad, tal como la postulaba el viejo marxismo.

Concretamente, sobre la relación entre religión y política -Aranguren siempre postuló la apertura de la ética a la religión-, hay posturas diferentes desde la izquierda a esa más clásica de Ovejero. Una apuesta por la convergencia y fecundación mutua ( $c f$. Díaz-Salazar, 2000) e incluso algunos intelectuales, como el marxista Michael Löwy -quien califica a la encíclica papal Laudato si como «antisistema»-, propugnan una abierta cooperación entre ecosocialismo, cristianismo de liberación y anticapitalismo (2019). Otra posición es la del teólogo jesuita González Faus (2011) que, al tratar del «naufragio de la izquierda» -entendida en su estricto sentido social y económico, diferente al político y cultural- acusa a ésta de haberse convertido en una pseudoizquierda, «izquierda de plástico» o «barata». Esta es la izquierda que, para Faus, ha entrado en crisis al haber efectuado un giro hacia posicionamientos socioeconómicos más propios de la derecha aunque suavizándolos con pequeñas reformas «lampedusianas» pero sin lograr una verdadera transformación estructural. A este respecto, es también conocida, al menos en ciertos círculos, la fórmula (¿mágica?) del escritor, filósofo y guionista Santiago Alba Rico para «poder seguir siendo de izquierdas» (2013): revolución económica, reformismo institucional y conservadurismo antropológico, o, en otras palabras, «una alianza entre el capitalismo más pragmático, el marxismo más ilustrado, el feminismo más humanista, el ecologismo más realista y el papa Francisco. ¿Es eso de izquierdas?...» Él mismo se lo pregunta y yo lo dejo planteado como una cuestión abierta para seguir investigando y reflexionando.

forms/d/e/1FAIpQLSdp9eOnVFgM0s_1AR5q7fv3XKFffcXKzYpVvGIQFLHZuONApA/ viewform» 


\section{Agradecimientos}

El artículo tiene su origen en una comunicación, revisada y ampliada, que se presentó al V Congreso sobre pensamiento filosófico contemporáneo. Bajo el título «Hegemonía, populismo y democracia radical», fue organizado por la Sociedad Asturiana de Filosofía (SAF) y se desarrolló en la Universidad de Oviedo entre el 26 y 28 de septiembre de 2019, a cuyos responsables quiero felicitar por organizarlo y llevarlo a cabo con éxito, además de agradecer la aceptación de mi trabajo.

\section{Bibliografía}

Alba Rico, Santiago (2013). ¿Podemos seguir siendo de izquierdas? (Panfleto en sí menor). Barcelona: Pol.len Edicions.

Aramburu Zudaire, Mikel (2017). Un creyente entre los "éxtasis" del tiempo: heterodoxia, secularización y laicidad en el pensamiento de José Luis L. Aranguren. Madrid: Ápeiron Ediciones.

- (2018). "España, una meditación política: Cataluña y Euskadi”. Revista Stultifera Vol. 1/1, pp. 45-59.

Aranguren, José Luis L. (1995 y 1996). Obras completas. Vols. 3 y 5. Edición de Feliciano Blázquez. Madrid: Editorial Trotta.

- (2005). La izquierda, el poder y otros ensayos. Edición de Antonio García-Santesmases. Madrid: Editorial Trotta.

- (2010). Filosofía y vida intelectual. Textos fundamentales. Edición de Carlos Gómez. Madrid: Editorial Trotta-UNED.

Bernabé, Daniel (2018). La trampa de la diversidad: cómo el neoliberalismo fragmentó la identidad de la clase trabajadora. Madrid: Ediciones Akal.

Bonete, EnRiQue (1989). Aranguren: la ética entre la religión y la política. Madrid: Editorial Tecnos.

Capella, Juan-Ramón (2019). Un fin del mundo: Constitución y democracia en el cambio de época. Madrid: Editorial Trotta.

Díaz, Elías (2007). "Aranguren: Ética y Política“. Revista Internacional de Pensamiento Político, II Época, Vol. 3, pp. 165-192.

Díaz Salazar, Rafael (2000). La izquierda y el cristianismo. Madrid: Editorial Taurus. 
Errejón, Íñigo y Mouffe, Chantal (2015). Construir pueblo: hegemonía y radicalización de la democracia. Barcelona: Editorial Icaria.

González Faus, José Ignacio (2011). El naufragio de la izquierda. Cuaderno no177. Barcelona: Cristianisme i Justícia.

Innerarity, Daniel (2018). Comprender la democracia. Barcelona: Editorial Gedisa.

- (2020). Una teoría de la democracia compleja: gobernar en el siglo XXI. Barcelona: Editorial Galaxia Gutenberg.

Löwy, Michael (2019). Cristianismo de liberación: perspectivas marxistas y ecosocialistas. Barcelona: El Viejo Topo. Ediciones de Intervención Cultural.

Mezzadra, Sandro y Neumann, Mario (2019). Clase y diversidad: sin trampas. Pamplona-Iruña: Katakrak Liburuak.

Ovejero, Félix (2018). La deriva reaccionaria de la izquierda. Barcelona: Editorial Página Indómita.

Panea Márquez, José Manuel (2015). “J.L. López Aranguren (1909-1996) y el problema de nuestro tiempo". Revista Internacional de Pensamiento Político, I Época, Vol.10, pp. 273-289.

Sánchez-Cuenca, Ignacio (2018). La superioridad moral de la izquierda. Madrid: Editorial Lengua de Trapo.

Recibido: 28/12/2019

Aceptado: 15/03/2020

Este trabajo se encuentra bajo una licencia de Creative Commons Reconocimiento-

NoComercial-SinObraDerivada 4.0 